\title{
IMIGRANTES AFRICANOS E NEGROS BRASILEIROS: a identidade imaginada na imprensa portuguesa e brasileira
}

\author{
Brazilian black and A frican immigrants: \\ the imagined identity in the Portuguese and Brazilian press
}

\begin{abstract}
Rosangela Ferreira de Carvalho Borges
D outora em Ciências Sociais/ Antropologia na PUC-SP, Mestre em Ciências da Religião (PUC-SP), jornalista e professora universitária. Afiliação: Pontifícia Universidade Católica de São Paulo (PUC-SP), São Paulo, SP - Brasil, e-mail: rosangelafcb@yahoo.com.br
\end{abstract}

\begin{abstract}
Resumo
O objetivo deste artigo é apresentar como é construída não só a identidade étnica dos imigrantes negros africanos dos PALOP (Países Africanos de Língua O ficial Portuguesa, nomeadamente Angola, Cabo Verde, G uiné-Bissau, Moçambique e São Tomé e Príncipe) e seus descendentes nos jornais portugueses Público, C orreio da Manhã e 0 E x presso, em 2003, 2004 e 2005, como também do negro brasileiro na revista R aça Brasil durante o mesmo período, num estudo comparado entre Brasil e Portugal. Procura-se, também, não privilegiar apenas os resultados por si mesmos, mas evidenciar a reflexão da relação entre mídia e identidade étnica e os vínculos das ações particulares e o contexto em que estas se dão. Este artigo é resultante da pesquisa de doutorado no Programa de Pós-G raduação em Ciências Sociais/ Antropologia da Pontifícia Universidade Católica de São Paulo - PUC-SP e no Instituto de Estudos Jornalísticos da Universidade de Coimbra, Portugal, concluída em $2008^{1}$.
\end{abstract}

Palavras-chave: Mídia imprensa; Identidade étnica; Imigrantes africanos; Negros brasileiros.

${ }^{1}$ Pesquisa de doutorado financiada pela Capes/ Brasil, CN Pq/ Brasil eFundação Calouste G ulbenkian/ Portugal. 


\begin{abstract}
As a main purpose this article presents, not only how the ethnic identity of the African black immigrants from the PALOP - Portuguese-speaking African Countries - and their descendents is built in the Portuguese Newspapers Público, Correio da Manhã and Expresso, in 2003, 2004 and 2005, as well the ethnic identity of the Brazilian black men in the magazine Raça Brasil during the same period. It also searches not to privilege just the results per se, but to enlighten the reflection about the relationship between the media, the ethnic identity and the private actions bonds and the context in which they occur. This article is result of the Ph.D thesis Pontifícia Universidade Católica de São Paulo-PUC-SP and the Universidade de Coimbra, Portugal, at the end of 2008.
\end{abstract}

Keywords: Press media; Ethinic identity; African Immigrants; African Brazilians.

\section{Identidade étnica e imigrantes africanos dos PALOP* na imprensa de Portugal}

Apresenta-se como princípio norteador da reflexão para este estudo que a mídia constrói identidades em seus noticiários e que a identidade étnica é constituinte de uma forma de identificação pertinente aos atores sociais que, em maior ou menor grau, está sendo remodelada no processo de globalização, indaga-se sobre quais as identidades étnicas construídas sobre os imigrantes negros africanos dos PALOP (Países Africanos de Língua $O$ ficial Portuguesa, denominadamente Cabo-V erde, São ToméePríncipe, Angola, MoçambiqueeG uinéBissau) nos jornais portugueses, diários, Públion, Correio da Manhã e o semanário 0 E x presso e sobre os negros brasileiros na revista Raça Brasil.

A investigação junto ao corpus de 163 peças recolhidas dos jornais portugueses Públion, Correio da Manhã e 0 Ex xresso, durante os anos de 2003, 2004 e 2005, noticiários referentes aos imigrantes negros africanos dos PALOP e seus descendentes, numa abordagem quali-quantitativa, por meio da análise de conteúdo e de discurso através da ferramenta computadorizada Statistical Pack age for Social Sciences - SPSS (CUNHA, 2007, p. 168-196), juntamente com entrevistas com liderançasvinculadas aosimigrantesnegros africanos dos PALOP em Portugal, que possibilitaram a conjugação de fatores diferenciados da realidade investigada, na totalidade dos jornais portugueses verificou-se que a identificação (nacionalidade ou etnia) dos imigrantes africanos e seus descendentes é apresentada pela mídia, em sua grande maioria, como PALOP, em 77 peças. Em segundo lugar aparecem empatadas as denominações africanos e cabo-verdianos com 30 peças, em terceiro guineenses, com 18 peças e, em quarto, angolanos, em 8 peças. Moçambicanos e santomenses não são citados em nenhuma das 163 peças.

Considerada a totalidade dos 32 temas elencados (acidente/ incidente; agenda; clandestinidade; condições sociais; crime; desemprego; educação; exploração; expulsão; família; habitação; legalização; máfia; prostituição; reagrupamento; religião; sem abrigo; saúde; trabalho; violência; cultura; naturalização; legislação; discriminação; estatística; segurança; integração; SEF- Serviço deE strangeiro eFronteira; terro rismo; economia; estudos sobre imigração e outros), os mais focados pelos três jornais analisados durante os três anos são: integração, com 28 peças, seguido de discriminação com 24 peças.

No cruzamento entre os temas mais focados em relação às nacionalidades ou etnias dos imigrantes negros africanos dos PALOP, o tema integração aparece relacionado mais à denominação PALO P (19 peças), o tema discriminação é a mais frequente para a denominação africano (12 peças), crime para a denominação cabo-verdiano (5 peças) e condições sociais para os angolanos (3 peças). $\mathrm{Na}$ totalidade dos três jornais durante os anos de 2003,

\footnotetext{
* Países Africanos de Língua O ficial Portuguesa.
} 
2004 e 2005, o tom negativo prevalece em 75 das peças. Os resultados recolhidos destas variáveis apontam para algumas tendências: a legitimação de uma identidade étnica construída nesses jornais cristalizando um perfil negativo sobre os imigrantes negros africanos dos PALOP refletido no tema discriminação, segundo mais apontado e um tom dominante, em sua maioria, negativo. A marcação desses sujeitos pela mídia impressa, a partir da nacionalidade e/ ou etnia, assinala a tendência de uma etnicização da imagem do imigrante, por meio da exclusão ou da marginalização na medida em que são definidos como "outros" ou forasteiros.

O temaintegração, o mais abordado, sinaliza para o crescimento na pressão migratória, os dilemas das políticas de imigração muitas vezes inconsistentes e inoperantes, uma vez que circulam entre os limites davalorização ereconhecimento da diferençacultural e do comunitarismo, do universalismo e da escolha individual dentro de um processo de integração condizente com os parâmetros sociais, culturais, históricos, políticos e econômicos de Portugal.

As culturas nacionais são tentadas a se voltar ao passado, recuar ao tempo perdido, ou seja, ao tempo em que a nação era "grande". Esse retorno oculta uma intenção de mobilizar as pessoas para que expulsem os "outros" que ameaçam sua identidade nacional. Trata-se, na verdade, de um universalismo por meio do particularismo e um particularismo por meio do universalismo (HALL, 2002, p. 56-57).

Para Alcestina Tolentino, presidente da Associação Cabo-Verdiana em Lisboa, Portugal, os noticiários na imprensa portuguesa com enfoque negativo interferem na autoestima principalmente dos jovens filhos de imigrantes. D e acordo com ela:

A autoestima fica muito para baix 0 . $\mathrm{N}$ ós pensamos ao trabalhar oom os nossosjovens, descendentes dos imigrantes cabo-verdianos, em muitos bairros degradados, em barracas, estão oncentrados no mesmo espạo. E ssas zonas de concentração são olhadas om desconfiança. São descritas pelosmedia comozonasdeinseguranç. U ma dasprimeiras coisasqueprecisamoséqueos órgãos decomunicação parem deutilizaroterm 0 "bairrosproblemátioos". Q uandosefala em imigração, comecam sempre com o "problema", ou 0 "problemátioo", 0 "'fenômeno". E osjovenssãovistos œmo 'problema'. 0 'problema' é falta de oportunidade. (TOLENTINO, 2008).

É preciso lembrar que a identidade e a diferença não são entidades preexistentes, naturalizadas, não são elementos passivos da cultura, mas têm que ser constantemente criadas e recriadas. Por esse motivo a identidade e a diferença têm a ver com a atribuição de sentido à vida social e com disputas em torno dessa atribuição feita pela mídia. A diferenciação envolve um trabalho discursivo, 0 fechamento e a marcação de fronteiras simbólicas. É porque as identidades são construídas dentro e não fora do discurso. Portanto, é preciso compreendê-las como produzidas em locais históricos e institucionais específicos, no interior de formações e práticas discursivas específicas, por estratégias e iniciativas específicas. A identidade étnica vai se reconstruindo e reconfigurando ao longo do processo histórico.

Nesse sentido, as estatísticas elaboradas a partir dos noticiários veiculados nos jornais $P$ úblico, 0 Ex xresso e Correio da Manhã, em 2003, 2004 e 2005, juntamente com os discursos recolhidos com o grupo de entrevistados, demonstram o quanto a mídia em Portugal ainda trabalha com a construção de uma identidade étnica negativa sobre os imigrantes negros africanos dos PALOP em Portugal, apesar da investigação em questão também apontar algumas tendências de mudanças significativas desse quadro em relação a esse tratamento negativo. Essa constatação é verificada através dos dados entre 0 cruzamento das variáveis tom dominante, meio e ano.

Em 2003, o tom negativo aparece em primeiro lugar com 20 peças, seguido do que se pretende neutro com 10 peças e, por último, 0 positivo com 7 peças. Já em 2004 o tom que se pretende neutro é que prevalece em 14 peças, seguido do negativo com 11 peças e positivo, com 8 peças. Embora em 2005 o tom negativo retorne em 44 peças, existe aqui uma divisão mais igualitária entre os tons positivo com 26 peças e que se pretende neutro, com 23 peças. Outro detalhe importante nessa modificação em 2005 é que, além de ser a primeira vez que o tom positivo aparece em segundo lugar, diferentemente dos anos anteriores em que 0 tom positivo sempre prevaleceu em último lugar.

Sobre essas modificações de tom negativo para tom positivo nos noticiários sobre os imigrantes negros africanos dos PALOP nos últimos anos, Rui Marques destaca o trabalho do ACIME - Alto Comissariado para a Imigração e Minorias Étnicas, órgão subordinado à Presidência do Conselho de Ministrosdo G overno Português, junto aosjornalistas:

D esde 0 prinćpio no A CIME nós procuramos em vários níveis, em vários caminhos, ter este trabalho de confiança nos jornalistas e que o nosso trabalho não é 
manipulador, nem de propaganda, procura ser um trabalho sério, de consistência, respeitando a liberdade editorial, respeitando as diferentes opiniões dos vários jornalistas, mantendooscanaisabertos com osjornalistas e percebendo que existem critérios para as notícias. (MARQUES, 2007).

Nota-se que o processo de uma construção identitária negativa sobre os imigrantes negros africanos dos PALOP e seus descendentes na mídia portuguesa, pelo menos no que se refere aos anos de 2003, 2004 e 2005, especificamente nos jornais Público, 0 E x presso e Correio da Manhã, pouco a pouco e de forma gradual e crescente começaa desencadearum discurso menos negativo.

No que tange ao papel dos jornalistas na construção da identidade, Ana Ribeiro Cruz, da SO S Racismo, Ong de combate ao racismo, localizada em Lisboa, Portugal, apresenta uma posição bastante diferenciada sobre o tema, na medida em que coloca a ênfase da problemática na formação que as universidades portuguesas dão aos estudantes do curso de Jornalismo. Para ela,

É importantequeojornalista saia da universidadecom a noção do papel dele na formação da consciência das pessoas. Q uando um jornalista escreve, tem que ter responsabilidade. É maisimportantevender uma notícia do que a confirmação da notícia? A lguma coisa está errada. Q uando um jornalista escreve uma notícia, tem queter consciência da influência queela tem naqueles que a leem. (CRUZ, 2006).

\section{Raça Brasil: a identidade étnica dos negros brasileiros em pauta}

Na revista Raça Brasil, dos 28 editoriais analisados, numa abordagem também qualiquantitativa, por meio da análise de conteúdo e de discurso através da ferramenta computadorizada Statistical Pack age for Social Scienoes - SPSS (CUNHA, 2007, p.168-196), juntamente com entrevistas com lideranças deO ngs vinculadas aos negros brasileiros, o temaautoestima, no conjunto, aparece em primeiro lugar com 7 peças e cultura, com 6 peças. Os resultados apontam para a linha editorial que Raça Brasil optou para abordar questões sobre o negro brasileiro. Portanto, se tratando do tema cultura ou autoestima a ideologia dos editoriais da revista Raça Brasil está imbricada pelo projeto de resgate da autoestima do negro.
0 tom dominante positivo encontrado nas 26 peças, na totalidade dos 3 anos analisados, concorda plenamente com as temáticas abordadas pela revista. Ou seja, a revista Raça Brasil busca construir uma identidade étnica do negro brasileiro também a partir de traços culturais diferenciadores, porém invertendo o que era considerado pelos outros veículos de comunicação como traços culturais diferenciadores negativos em positivos, por isso a predominância de matérias sobre beleza negra (cabelo, maquiagem), sucesso (ascensão econômica e social), comportamento, com destaque para "celebridades" negras (cultura) que normalmente já possuem visibilidade nos diversos veículos de comunicação, principalmente a televisão, por ser a mídia que tem maior audiência, maior alcance nas diversas camadas sociais, nos variados espaços geográficos. Assim, Raça Brasil aponta para a tendência editorial na qual se quer que 0 reconhecimento, 0 resgate, a valorização da autoestimasejam osprincipais elementosnaconstrução da identidade étnica do negro brasileiro: celebrar a diferença, afirmando as qualidades do negro brasileiro.

Não se pode esquecer que, embora os primeiros números da revista nos idos de 1996 tenham chegado às mãos da população negra de variadas classes sociais por conta daprópria novidade do produto editorial, a revista quer falar para "uma determinada população negra": a população negra constituída notadamente por mulheres da classe média, com poder de consumo.

D essa forma, a afirmação étnica corresponde muitas vezes a uma diferenciação cultural sustentada em recursos econômicos autorizados por um poderoso apelo de um promissor mercado de negócios com base na etnia.

Flávio Carrança, jornalista e membro fundador da COJIRA - Comissão de Jornalistas para a Igualdade Racial do Sindicato dos Jornalistas de São Paulo, considera que Raça Brasil teve um papel didático na reorientação da formação da identidade étnica do negro:

A revista Raça Brasil teve um determinado momento em quesedissesseassim: nãoéfeio ser negro, podeser uma coisa legal. E la dissepara o mercado publicitário queera possível, que este públioo podia consumir qualquer tipo deproduto, queeleex istia equetinha poder deconsumo. $\mathrm{N}$ este sentido ela inverteu um poun o discurso que era do movimento negro que era 0 de vitimização. $\mathrm{N}$ este sentido, a revista teve um papel didátioo e reorientou a formação da identidadetalvez em outro sentido. E mbora reportando valores atéqueponto conservadores, mas ela teve um papel de mudança. (CARRANÇA, 2008). 
Para Nilza Iraci, comunicadora social e coordenadora do Programa de Comunicação da Ong Geledes, organização de mulheres negras que tem por objetivo institucional combater o racismo e 0 sexismo, valorizar e promover as mulheres negras em particular e a comunidade negra em geral, fundada em 1988, a revista Raç Brasil cumpre bem o seu papel como uma produção editorial para o negro de um mercado consumidor segmentado de massa e que esse papel muitas vezes não é bem compreendido pelo movimento negro que tem demonstrado desde 0 início do lançamento da revista uma expectativa que não é condizente com a proposta da revista:

Q ual a grande questão colocada pela revista Raça edos ativistas da questão racial? Para a grandemaioria dos movimentos sociais, organizações governamentais enãogovernamentais e demais instituiōoes que atuam nas fronteiras das relacões raciais, esperava-se da revista Raça a possibilidade, dado 0 seu caráter inovador de uma publicação comercial e segmentada de uma aliada estratégica, quase uma porta-voz, uma mediadora da questão da visibilidade do racismo para a sociedade brasileira. (IRACI, 2008).

A reflexão de Wieviorka (2002) sobre 0 individualismo moderno esclarece bem os conflitos entre o movimento negro brasileiro e a revista Raça Brasil. Para Wieviorka (2002, p. 57) existem duas percepções principais da transformação cultural que coexistem desde os anos 60 do século XX: uma que privilegia a maneira como o individualismo moderno é vivenciado na própria experiência de cada pessoa para a qual aidentidade comporta dimensões culturais que não se transcrevem necessariamente em uma ação coletiva; a outra que considera as significações e as orientações culturais conduzidas pelos movimentos coletivos. Ainda sobre o individualismo moderno, Wieviorka (2002, p. 58) informa que ele "representa aos nossos olhos uma das principais forças de ascensão das afirmações identitárias coletivas; constitui uma das componentes das diferenças culturais contemporâneas."

Quanto àquestão dapropostadeconstrução de uma identidade étnica do negro brasileiro na revista, na qual são elencados traços culturais difenciadores positivos como a valorização da autoestima, a beleza, a ascensão social individual, a inserção no mercado de consumo, a visibilidade positiva do negro na mídia, novamente é Nilza Iraci da Ong Geledes quem apresenta a seguinte consideração:
A revista Raca surpreendeo mercado editorial com uma visão diferenciada do negro: odedassemédia, onnsumidor. A questão fundamental é que se para os movimentos sociais negros, ela se prendia a uma visa de consumo, para negros em geral ela significava um nex onão apenas de visibilidade mas também de autoestima. 0 mercado editorial feminino conta com inúmeras revistas ( $\mathrm{N}$ ova, $\mathrm{M}$ arieC laire, Claudia), om abordagens mais ou menos semelhante, om assuntos mais ou menos aprofundados. $\mathrm{N}$ esse sentido cabe a nós, enquanto movimento negro produzirmos uma publicação que possa ser um instrumento não apenas de visibilidade da questão racial, mas capaz de dialogar oom toda a sociedade, e capaz dereverter oproblema doracismo, da discriminação e preconciito que assola esse país e penaliza milhões de pessoas em função desua raça. $N$ ãopodeser simplesmente a troca de clichês racistas por dichês militantes. $\mathrm{N}$ ão se pode condenar a revista Raça por não cumprir as ex pectativas apenas de um segmento da população negra, mas na medida do possível estimulá-la para que também trate de questões para além do consumo. (IRACI, 2008).

De acordo com Rosangela Aparecida Hilário, coordenadora do curso de Pedagogia da Universidade da Cidadania Zumbi dos Palmares UNIPALMARES, que por meio do Instituto A froBrasileiro deEnsino Superiorfoi criadapela Portaria no 3.591, de 13/ 12/ 02, do Ministério da E ducação, e inaugurada em 21/11/ 03, a revista Raça Brasil é uma publicação que contribui para reverter a imagem negativa da estética negra até então veiculada na mídia.

A revista Raça Brasil tem contribuído para reverter a imagem absolutamente inverídica de que negro não é bonito, não vende a não ser por meio de apelo de uma sensualidade pornográfica e da reprodução da estética europeia. M asum trabalhodeconstrução deuma (nova) identidadeétnica, não acreditonão. A téporquea revista não tem uma preocupação direcionada para disautir em profundidade as grandes questões relacionadas à construção da identidadeétnica. (HILÁRIO , 2008).

Assim, nos resultados da análise de conteúdo no SPSS, os discursos dos entrevistados apontam para a construção nas mídias impressas brasileira e portuguesa de uma identidade étnica dos imigrantes negros africanos dos PALOP em Portugal e dos negros brasileiros no Brasil, porém apontam também que os caminhos percorridos pelas mídias impressas de Portugal e do Brasil neste sentido são distintos no processo e aproximativos 
no resultado final. D este modo, os noticiários dos jornais portugueses Público, Correio da Manhã e 0 E x presso, em 2003, 2004 e 2005 tendem à construção de uma identidade étnica dos imigrantes negros africanos dos PALOP ainda bastante fixada em traços físicos e culturais diferenciadores para legitimar a oposição entre os "outros" - excolonizados, imigrantes e asilados, os negros - em relação ao "nós" - os colonizadores, os brancos, os "nacionais portugueses".

A revista brasileira Raça Brasil, por sua vez, durante o mesmo período, potencializa em seus editoriais também os traços físicos e culturais diferenciadoresparaa construção daidentidadeétnica do negro brasileiro, porém sua construção é fixada não apenas da sua condição de nós, de pertença à sociedade brasileira como em diferenças celebrativas, afirmativas, a partir do que a revista considera como as principais qualidades do negro brasileiro. Em ambos os casos, a construção da identidade étnica de imigrantes negros africanos dos PALOP e negros brasileiros nas mídias impressas operou o tempo todo um processo rotativo de distinção/ reconhecimento, reconhecimento/ distinção dos traços diferenciadores físicos e culturais.

\section{Aquém e além-mar: proximidades, distâncias e semelhanças nas recorrências temáticas da imprensa portuguesa e brasileira}

Como se depreende nesta exposição, na revista Raça Brasil os dados apontaram a temática autoestima como a mais focada pela revista. Os demais temas porventura pautados pela revista, como condições sociais, educação, legislação, discriminação, beleza, trabalho, convergem sempre para a legitimação da temática autoestima, num processo centrado.

Nos jornais portugueses Públio, C orreio da Manhã e 0 E x presso, verificou-se que na totalidade dos três jornais a identificação da nacionalidade e/ ou etnia a que pertencem os imigrantes africanos e seus descendentes oriundos dos países africanos de Cabo Verde, São Tomé e Príncipe, Angola, Moçambique e Guiné-Bissau é apresentada em sua maioria como PALOP. Em segundo lugar, os mais focados aparecem empatados com as denominações de africanos e cabo-verdianos. No que se atribui à totalidade dos temas, os mais visados, no conjunto dos jornais, são: integração e discriminação. Já no cruzamento entre os temas mais focados em relação às nacionalidades ou etnias dos imigrantes negros africanos dos PALO P, integração se relaciona mais à denominação PALOP e discriminação à denominação africano, enquanto 0 atributo caboverdianos está relacionado ao crime e angolanos a condições sociais. $\mathrm{O}$ tom dominante das notícias é 0 negativo.

A tendência de uma construção da identidade étnica com base na etnicização da imagem dosimigrantesnegros africanos dos PALO P é, justamente, para legitimar a exclusão ou a marginalização dos mesmos, visando demarcar a fronteira entre os "outros", os "forasteiros", os imigrantes negros africanos dos PALOP e seus descendentes em detrimento ao "nós", os portugueses, os de "dentro".

Apesar dos resultados obtidos ainda confirmarem um tom negativo predominante na totalidade dos três anos analisados, quando associados à cobertura referente aos imigrantes negros africanos dos PALO P e seus descendentes, a investigação apontou também uma progressiva tendência para um discurso midiático entre 0 tom que se pretende neutro e o positivo, quando os resultados foram obtidos ano a ano. Em face do exposto, parece que, de forma gradual, começa-se a desencadear um discurso midiático menos negativo sobre essas populações, na medida em que a integração como tema mais focado durante os três anos pesquisados demonstra também um maior interesse da mídia portuguesa pelas questões que envolvem a identidade étnica e a cultura do "outro". É visível o reconhecimento por parte das próprias mídias do crescimento da pressão migratória, dos dilemas das políticas de imigração em Portugal, muitas vezes inconsistentes e inoperantes, na medida em que tais políticas circulam entre os limites da valorização e 0 reconhecimento da diferença cultural e do comunitarismo, do universalismo e da escolha individual condizente com os parâmetros sociais, culturais, históricos, políticos e econômicos do país, já que as culturas nacionais parecem sempre tentadas a se voltar ao passado, a recuar ao tempo perdido de quando a nação era "grande", em olhar o "outro" como uma ameaça para a identidade nacional. A afirmação da identidade traduz 0 desejo dos diferentes grupos sociais para garantir 0 acesso privilegiado ao s bens sociais, numa estreita conexão com relações de poder. 
A demarcação de fronteiras entre "nós" e os "outros" não é uma questão de simples categoriais gramaticais, mas indicadores de posições fortemente marcadas na sociedade portuguesa. D eter o privilégio de classificar significa também deter o privilégio de atribuir diferentes valores aos grupos classificados. Assim, aidentidade quetem aver com umaatribuição de sentido ao mundo social e também com disputas em tomo dessa atribuição, já que as identidades são construídas em locais históricos e institucionais específicos, no interior de formações e práticas discursivas específicas, a mídia tem as suas estratégias e iniciativas específicas neste processo.

No que se refere à análise do corpus dos 28 editoriais recolhidos da revista Raça Brasil, os resultados dos cruzamentos dos dados referentes ao tema autoestima e ao tom positivo, na maioria dos editoriais, apontaram para a tendência de uma construção daidentidade étnica do negro brasileiro na revista por meio de traços culturais diferenciadores positivos, nos quais a diferença é celebrada na afirmação do que a própria revista considera como as principais qualidades dos negros brasileiros. E quais são estas qualidades dos negros brasileiros eleitas nos editoriais de Raça Brasil?

A predominância de matérias sobre beleza negra, sucesso (ascensão econômica e social), destaque para "celebridades" negras com grande visibilidade no mundo midiático contém a resposta a esta pergunta que a revista não quer calar. 0 seu posicionamento em favor da valorização da autoestima do negro brasileiro é explícito desde 0 lançamento do primeiro número da revista, em 1996.

A afirmação da identidade étnica em Raça Brasil está vinculada a uma diferenciação cultural que permite responder ao poderoso apelo de um promissor mercado de negócios com base na etnia.

Deste modo, os resultados da análise de conteúdo e de discurso pontuaram, sim, uma tendência de construção nas mídias impressas brasileira e portuguesa de uma identidade étnica sobre os imigrantes negros africanos dos PALOP em Portugal e os negros brasileiros no Brasil, porém tal construção ressalta também que os caminhos percorridos por cada uma das identidades são distintos no processo e próximos no resultado final.

Os noticiários dos jornais portugueses Públion, Correio da Manhã e 0 Ex xresso, em 2003, 2004 e 2005, procuram construir uma identidade étnica dos imigrantes negros africanos dos PALO P apresentando traços culturais diferenciadores para fixaraoposição entreos "outros", os ex-colonizados, os imigrantes e asilados, os negros, em relação ao "nós", os portugueses, os colonizadores, os brancos, os "nacionais".

Já a revista Raça Brasil potencializa em seus editoriais também traços culturais diferenciadores do negro brasileiro, mas para fortalecer, legitimar a identidade étnica e sua construção numa diferença celebrativa, fixada na afirmação do que considera como as qualidades principais do negro brasileiro.

Durante 0 estudo, nota-se também que os imigrantes negros africanos dos PALOP raramente têm a palavra nos jornais portugueses, uma vez que o estudo apontou as lideranças das associações de imigrantes, SO SRacismo e o ACIME como a "voz" predominante dos noticiários.

Os negros africanos dos PALOP em Portugal ainda vivenciam um processo de inserção iniciado na década de 1970. Com a descolonização de Angola, Cabo Verde, São Tomé e Príncipe, Moçambique e Guiné Bissau, em 1975, abriu-se em Portugal 0 ciclo da imigração, não só com 0 repatriamento dosportuguesesradicadosnascolônias, mas também com o início de uma migração africana procedente destes países. A independência das excolônias colocou aquestão, ou perca, danacionalidade portuguesa pelos indivíduos nascidos, ou domiciliados nas ex-colônias antes dessa mudança.

A resposta para tal problema foi construída politicamente por meio da alteração da lei da nacionalidade, que até então se baseava no critério ius solis (atribuição da nacionalidade a todos os que nasceram no país) e passa a vigorar 0 critério do ius sanguinis (atribuição da nacionalidade a todos os descendentes de nacionais do país). Para Rui Pires (2003, p. 127) este procedimento transparece a distinção de tratamento por parte do governo de Portugal para a população branca residente nas ex-colônias e para a população negra.

Não podendo exerceraquela selectividadenuma base racial, as autoridades políticas portuguesas da época resolvem o dilema - facilitação do repatriamento dapopulação branca/ dificuldade do fluxo de refugiados negros - remetendo para o critério do ius sanguinis a possibilidade de conservação da nacionalidade pelos naturais ou domicialiados nas ex-colônias. O critério transparecenadefinição dasprincipais excepções ao princípio geral da perca da nacionalidade então adoptado, onde se estipula que 
conservavam a nacionalidade, depois da data da independência, "os seguintes portugueses domiciliados em território ultramarino tornado independente: os nascidos em Portugal continental enasilhas adjacentes; osnascidosno estrangeiro de pai ou mãe nascidos em Portugal ou nas ilhas adjacentes ou de naturalizados; a mulher casada com, ou viúva ou divorciada de, português dos referidos nas alíneas anteriores e os filhos menores deste." (D ecreto-Lei no 308A/ 75, Art.1, n.․ 1 apud PIRES, 2003, p. 127).

A história subsequente da imigração em Portugal foi profundamente marcada pelos efeitos desta medida legislativa, na medida em que diferenciou o repatriamento das ex-colônias da imigração de estrangeiros com a mesma origem, definiu as condições jurídicas e simbólicas de integração dos futuros imigrantes, estrangeiros, e dos seus descendentes, na sociedade portuguesa e contribuiu para que os mesmos fossem colocados, inclusive pelas mídias portuguesa, no patamar do "outro" em relação ao "nós". E, embora, novas medidas no âmbito da integração atualmente em Portugal busquem amenizar esta dicotomia, os resultados apresentados nesta investigação demonstram que persiste ainda uma forte discriminação racial na sociedade portuguesa em relação aosimigrantesnegros africanos dos PALO P .

Apesar de algumas mudanças no tratamento menos negativo pelas mídias quando 0 tema é a imigração em Portugal, os imigrantes negros africanos dos PALOP ainda são marcados como os "invisíveis", aqueles que "não existem", a não ser quando podem ser apresentados sob a luz da criminalidade, da degradação, dos "fora do lugar". Por sua vez, estas populações que convivem com a falta de acesso digno à moradia e ao emprego formal, aos serviços de saúde pública, juntamente com a discriminação e o racismo, estão cada vez mais confinadas a determinados espaços: centros associativos, família, bairro.

Nos editoriais da revista Raça Brasil, a voz predominante é a institucional, apontando como temáticas principais a autoestima e a cultura, num enfoque para as "celebridades midiáticas". No entanto, se por um lado a revista coloca as "celebridades midiáticas" como exemplo para a valorização da autoestima do negro brasileiro - que embora represente 49\% da população do Brasil, na pirâmide social e econômica tem os piores índices de acesso à saúde, à educação formal, à moradia e os salários mais baixos - por outro, relega essa maioria da população negra ao patamar dos "invisíveis", dos que "não existem", dos "outros", quesendo igual ao "nós" porquetodos são brasileiros, ainda são os "outros", porque negros.

Os que "existem" como "celebridades", negros de "sucesso", apresentados na revista como os exemplos de valorização da autoestima para uma pequenaclassemédia negra, com acesso aos serviços de saúde, a educação formal, aos bens de consumo, à moradia digna também são colocados como os "outros", em que o reconhecimento e a diferença física são valorizados, exotizados. São os "outros", os negros brasileiros estetizados, que a revista pretendeveicular como padrão paraagrandemaioria da população negra brasileira.

O discurso da revista Raca Brasil sobre 0 negro é estético, um modo de subjetivação baseado no individualismo que faz do sucesso pessoal 0 padrão geral de reconhecimento identitário. A questão do negro no Brasil tem um legado histórico muito mais abrangente: mais de 300 anos de escravidão; um processo de mestiçagem iniciado já nos primórdios dacolonização parasuprir as diversas necessidades do projeto colonizador português e mais tarde, nosfinais do século X IX, com aideologia do branqueamento biológico; a extinção da escravidão sem o mínimo de comprometimento quanto à integração do negro à sociedade; a ideia da democracia racial que colaborou muito para a negação da existência do racismo no Brasil.

No texto A questão do negro: velhos e novos desafios 1991, Josildeth Gomes Consorte enfatiza a importância de indagar sobre a questão da identidade do negro no Brasil, dentro de uma perspectiva da existência de impasses que a atravessam.

A questão da identidade negra, colocada em pauta há mais de dez anos pelo movimento negro, encontra-se, desde então, atravessada por uma série de impasses na medida em que, ao colocar no centro do debate a construção da diferença, exige um amplo repensar dos elementos que entram no seu processo de construção e uma série de definições. Q uem é o negro brasileiro?Porondepassasuaidentidade? No retorno à África, em busca de suas raízes? Na sua história desde lado do Atlântico? A identidade negra tem que ser, necessariamente, una ou é possível considerá-la multifacetada, a partir das múltiplas experiências vividas aqui? É possível pensarumaidentidadenegrasem pensar 
uma cultura negra? Em que circunstâncias se vem efetivamente produzindo e reproduzindo uma cultura negra no Brasil? Quais os seus espaços e que cara ela tem? (CONSORTE, 1991, p. 91).

Assim, a revista Raça Brasil longe de colocar em evidência ou discussão as razões estruturais do racismo e da discriminação, e as mudanças que tal situação exige, aponta para saídas individuais, para as oportunidades que se abrem a cada um, para a ascensão social como via de solução para o problema.

\section{REFERÊNCIAS}

CONSORTE, Josildeth Gomes. A questão do negro: velhos e novos desafios. São Paulo em Perspectiva, v. 5, n. 1, p. 91, 1991.

CUNHA, Isabel. O SPSS e os estudos sobre os media e o jornalismo. In: LAGO, Cláudia; BENETTI, Márcia (O rg.). Metodologia de pesquisa em jornalismo. Petrópolis, Vozes, 2007.

HALL, Stuart. A identidade cultural na pósmodernidade. Rio de Janeiro: D P\&A, 2002.
PIRE S, Rui Pena. Migrações e integração: teoria e aplicações à sociedade portuguesa. O eiras, Portugal: Celta, 2003.

WIEVIO RKA, Michel. A diferença. Lisboa, Portugal: Fenda, 2002.

\section{Entrevistas concedidas à autora}

CARRANÇA, Flávio. São Paulo, Brasil, fevereiro de 2008.

CRUZ, Ana Ribeiro. Lisboa, Portugal, novembro de 2006.

HILÁRIO. Rosangela Aparecida. São Paulo, Brasil, Maio de 2008.

IRACI, Nilza. São Paulo, Brasil, Abril de 2008.

MARQUES, Rui. Lisboa, Portugal, Março de 2007.

TO LENTINO, Alcestina. Lisboa, Portugal, Novembro de 2006.

Recebido: 08/ 10/ 2008 Received: 10/ 08/ 2008

Aprovado: $21 / 11 / 2008$

A pproved: $11 / 21 / 2008$ 